\title{
Herpes Iris of Bateman in a 14-Year-Old
}

\author{
Saipreethi P.. ${ }^{1}$, Vijayakumar S. ${ }^{2}$, Sowmya Naga Dogiparthi' ${ }^{3}$, Jeyakumari Jeevan ${ }^{4}$
}

${ }^{1}$ Department of Dermatology, Venereology and Leprosy, Shri Sathya Sai Medical College and Research Institute, Sri Balaji Vidyapeeth, Ammapettai, Tamilnadu, India. ${ }^{2}$ Department of Dermatology, Venereology and Leprosy, Shri Sathya

Sai Medical College and Research Institute, Sri Balaji Vidyapeeth, Ammapettai, Tamilnadu, India. ${ }^{3}$ Department of Dermatology, Venereology and Leprosy, Shri Sathya Sai Medical College and Research Institute, Sri Balaji Vidyapeeth, Ammapettai, Tamilnadu, India. ${ }^{4}$ Department of Dermatology, Venereology and Leprosy, Shri Sathya Sai Medical College and Research Institute, Sri Balaji Vidyapeeth, Ammapettai, Tamilnadu, India.

\section{INTRODUCTION}

Erythema multiforme (EM) is an acute self-limited polymorphous eruption, probably mediated by deposition of the immune complex in the superficial microvasculature of the skin. Most common causes include infectious agents followed by drugs and contact dermatitis. Approximately $50 \%$ cases are idiopathic.

We report a case of a 14-year-old girl with vesiculobullous form of erythema multiforme eruptions with typical target lesions. Patient had recurrent episodes of herpes labialis for the past 4 years and recurrent erythema multiforme like lesions for the past 2 yrs. Serological investigation specific for herpes simplex type 1 virus concluded the etiological factor in this patient. There are only few case reports in India with Herpes Iris of Bateman kind of erythema multiforme lesions with positive infective trigger, and hence reported for its classical findings in this patient.

\section{PRESENTATION OF CASE}

A 14-year-old girl presented to our department with a vesiculobullous eruption over check, lips, arms, legs and trunk for a period of 2 weeks. Lesions initially started over the upper limbs and then progressed to involve the oral cavity and lower limbs. Detailed history revealed similar conditions have occurred in the past, totalling 4 episodes over 2 years including the present one with recurrent attacks of fluid filled grouped lesions around the mouth suggestive of herpes simplex for the past 4 years. The patient had obtained treatment in an outside hospital on the second day of the eruption, and on stopping the drugs had an aggravation. Every time, lesions over the body appeared 2 to 3 days following the onset of herpes simplex. History of photo aggravation, malar rash, discoid rash, skin tightness or other symptoms suggestive of connective tissue disorder, any recent/regular drug intake, over the counter medications, exposure to any chemical compounds, cough, cold or difficulty in breathing, fever and joint pain were all absent. General and systemic examination were normal. Dermatological examination revealed multiple vesicles with few coalescing to form bullae characteristically forming around central bullous lesionHerpes Iris of Bateman were present over both upper limbs, lower limbs and few scattered lesions over the neck, chest, abdomen and back. [Figure. 1] No lesions over the scalp, palms \& soles and genitalia. Oral cavity showed erosions and bullae. Target lesions with all three zones were present over the trunks and limbs. [Figure. 2]
Corresponding Author:

Dr. Saipreethi P.,

Junior Resident,

Department of Dermatology, Venereology \& Leprosy, Shri Sathya Sai Medical College \& Research Institute, Sri Balaji Vidyapeeth, Ammapettai, Tamilnadu, India.

E-mail: saipreethi1993@gmail.com

DOI: $10.14260 / j e m d s / 2020 / 560$

How to Cite This Article:

Saipreethi P, Vijayakumar S, Dogiparthi SN, et al. Herpes iris of Bateman in a 14-yearold. J Evolution Med Den Sci 2020;9(35): 2577-2579, DOI:

$10.14260 /$ jemds $/ 2020 / 560$

Submission 21-05-2020,

Peer Review 17-07-2020

Acceptance 23-07-2020,

Published 31-08-2020.

Copyright (C) 2020 JEMDS. This is an open access article distributed under Creative Commons Attribution License [Attribution 4.0 International (CC BY 4.0)] 


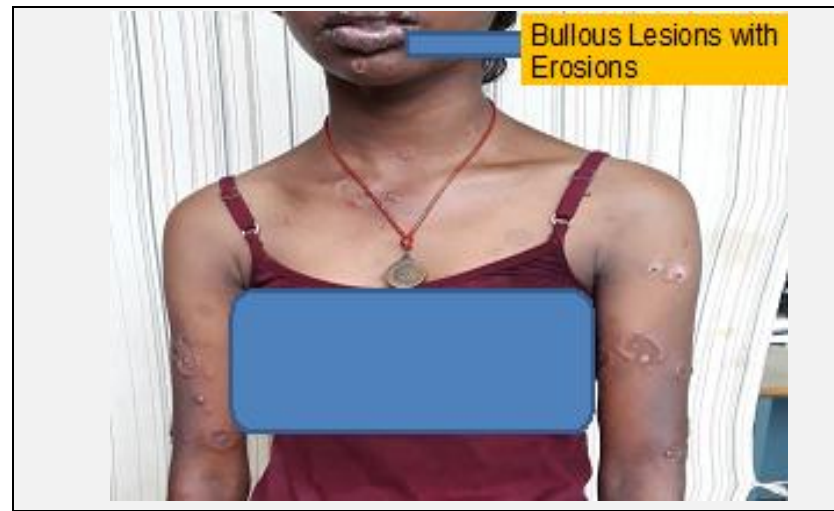

Figure 1. Bullous Lesions over the Upper Limbs and Lips with Erosions
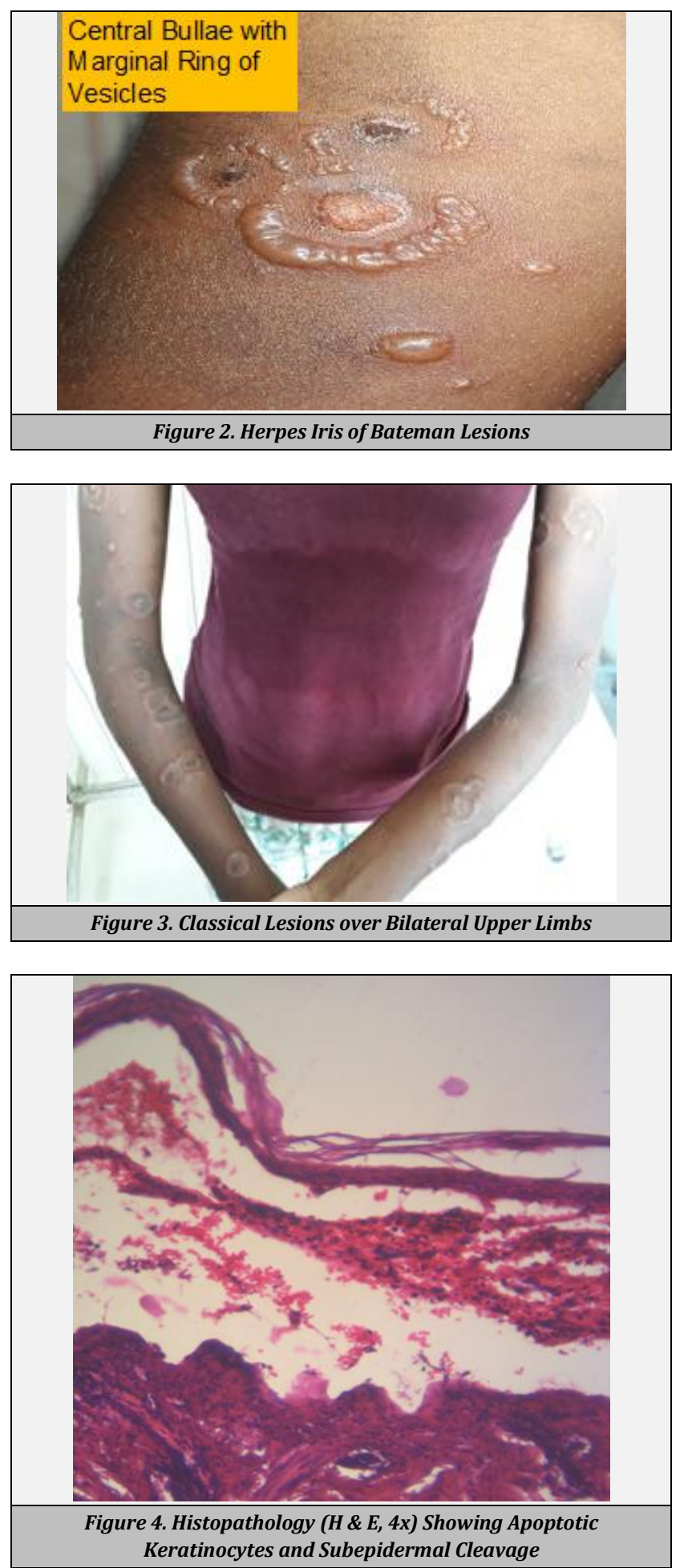

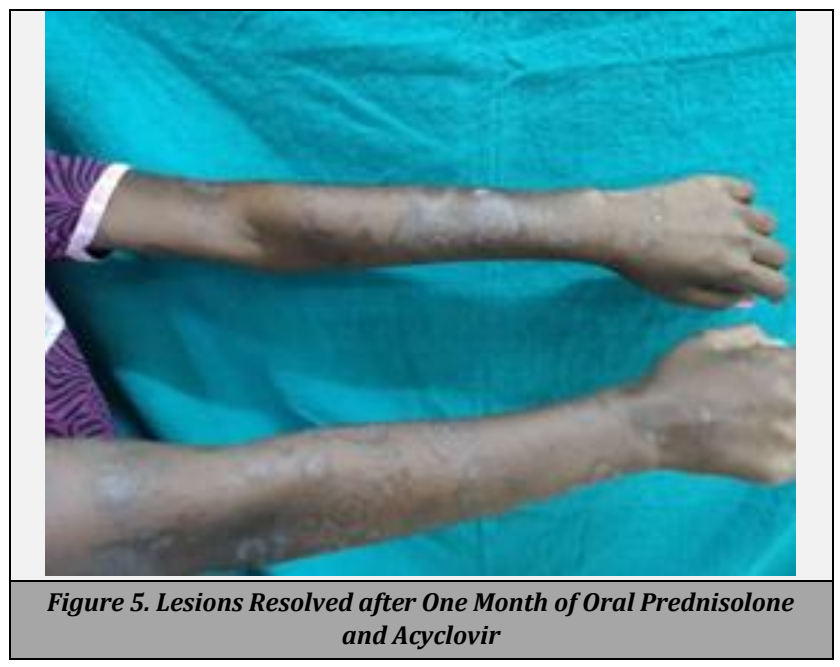

Complete blood count was normal. Liver enzymes were normal. Mild elevation of erythrocyte sedimentation rate was noted. Serological results showed high IgG HSV1 titre up to $163 \mathrm{RU} / \mathrm{mL}$ along with the histopathological features of the biopsy of intact bullae over left hand showing sub epidermal cleavage along with apoptotic keratinocytes. [Figure-4]

\section{DISCUSSION}

Based on the history, clinical findings and serological tests, diagnosis of erythema multiforme major is made with the herpes simplex 1 infection as the trigger causing the herpes iris of Bateman lesions. Herpes Iris of Bateman is a distinctive skin lesion noted in certain patients of erythema multiforme major that is characterized by a central bulla over an erythematous background and a ring of vesicles at the margin. ${ }^{1}$ most common causes include Herpes simplex virus and mycoplasma pneumonia. Other infectious causes includes vaccinia, varicella, adenovirus, cytomegalovirus, hepatitis $B$, coxsackie virus, parvovirus, human immunodeficiency virus, Parapoxvirus, chlamydia, salmonella, Histoplasma and dermatophytes. ${ }^{2}$ Drugs induced causes includes barbiturates, phenytoin, lamotrigine, carbamazepine, valproic acid, penicillin, sulphonamides, azithromycin, tetracyclines, fluconazole, allopurinol, NSAIDs, ethosuximide and nevirapine. ${ }^{2}$ Allergic contact dermatitis caused by nickel, cobalt, aluminium and metals may present with similar lesions. Erythema multiforme major must be differentiated from chronic bullous disorder of childhood which classically presents with "string of beads" sign. ${ }^{3}$ Erythema multiforme is self-limiting and recurrent whereas chronic bullous disorder of childhood runs a chronic course. ${ }^{4}$ Other differential diagnosis to be considered are allergic contact dermatitis, drug reactions and pemphigus vulgaris. Patient was started on suppressive doses of acyclovir $400 \mathrm{mg}$ twice daily along with oral prednisolone $0.3-0.5 \mathrm{mg} / \mathrm{Kg} /$ day for 1 month and gradually tapered. Acyclovir is an antiviral agent specific for infections caused by herpes group of viruses. Acyclovir is phosphorylated into acyclovir monophosphate by HSV thymidine kinases and further activated into acyclovir triphosphate. Triphosphate form inhibits viral DNA polymerase preventing elongation of DNA chains and replication of DNA virus. Suppressive therapy is indicated in 
patients with recurrent erythema multiforme in whom the possible etiology of herpes simplex virus can be established. Valacyclovir showed good results in acyclovir unresponsive recurrent herpes associated erythema multiforme in few studies. ${ }^{5}$

Patient was followed up on $1^{\text {st }}$ month and oral prednisolone was withdrawn, there was resolution of erythema multiforme lesions with no recurrence up to one year on acyclovir prophylaxis. Post inflammatory pigmentation noted over the resolved sites. [Figure-5] Patient did not develop any lesions 6 months post treatment and she is still visiting our department at monthly intervals for follow up.

Financial or Other Competing Interests: None.

\section{REFERENCES}

[1] Roujeau JC. Erythema multiforme. In: Wolff K, Goldsmith LA, Katz SI, et al, eds. Fitzpatrick's dermatology in general medicine. $7^{\text {th }}$ edn. New York: McGraw-Hill 2008:343-9.

[2] Haldar B, Ghosh S, Haldar S. Cutaneous vascular responses. In: Valia RG, Valia AR, eds. IADVL Textbook of dermatology. $3^{\text {rd }}$ edn. Mumbai, India: Bhalani Publishing House 2008: p. 656.

[3] Rao CL, Hall RP. Linear immunoglobulin A dermatosis and chronic bullous disease of childhood. In: Wolff $\mathrm{K}$, Goldsmith LA, Katz SI, et al, eds. Fitzpatrick's dermatology in general medicine. $7^{\text {th }}$ edn. New York: McGraw-Hill 2008:485-90.

[4] Kumar P, Anand V, Hassan S. Herpes iris of Bateman. Indian Dermatol Online J 2014;5(Suppl 2):S138-9.

[5] Kerob D, Assier-Bonnet H, Esnault-Gelly P, et al. Recurrent erythema multiforme unresponsive to acyclovir prophylaxis and responsive to valacyclovir continuous therapy. Arch Dermatol 1998;134(7):876-7. 